\title{
Rivers in transition
}

\author{
Rivers run through nearly every landscape on Earth. Ascertaining the influence of this flux on carbon \\ dynamics is necessary for a full understanding of the climate system.
}

Rivers affect landscape structure and function to a much greater extent than might be expected from the fraction of the Earth's surface they cover. Rivers redistribute material as they flow, carving out canyons and building new land offshore. These morphological consequences of river flow are evident in any topographic map of the Earth's surface.

But rivers are also in perpetual exchange with the atmosphere, ocean and land. Not least because of this connectivity with many of the Earth's spheres, rivers themselves are significant - if hitherto under-studied - sites of biogeochemical activity. A collection of articles from this issue of Nature Geoscience and our archive, gathered together in a web Focus (http:// go.nature.com/PnogGz), explores some of the ways in which rivers contribute to the functioning of the environment.

The basis of a river's influence on the Earth's surface lies in its drainage network, shaped not only by past climate, but also by the deformation of the Earth's crust over millions of years (see Article on page 744). Once established, river networks collect and transport debris, with potentially far-reaching consequences. For example, rivers in Taiwan channel significant quantities of vegetative carbon from the tops of mountains to the depths of the ocean (Nature Geosci. 1, 759-762; 2008). This riverine transport of organic matter can result in a net drawdown of atmospheric carbon dioxide concentrations if the material makes it all the way down to the sea floor.

But rivers do not simply funnel land-based matter to the sea. Instead, evidence is accruing that only a portion of the organic material that enters a river network actually makes it to the ocean (Nature Geosci. 2, 598-600; 2009). A substantial amount, it seems, is either buried in sediments or broken down and released to the atmosphere en route. In the US, for instance, streams and rivers have been estimated to release $97 \mathrm{Tg}$ carbon to the atmosphere each year, equivalent to around $10 \%$ of the net carbon uptake of the entire US ecosystem (Nature Geosci. 4, 839-842; 2011). And as noted in a Letter on page 710 of this issue, streams

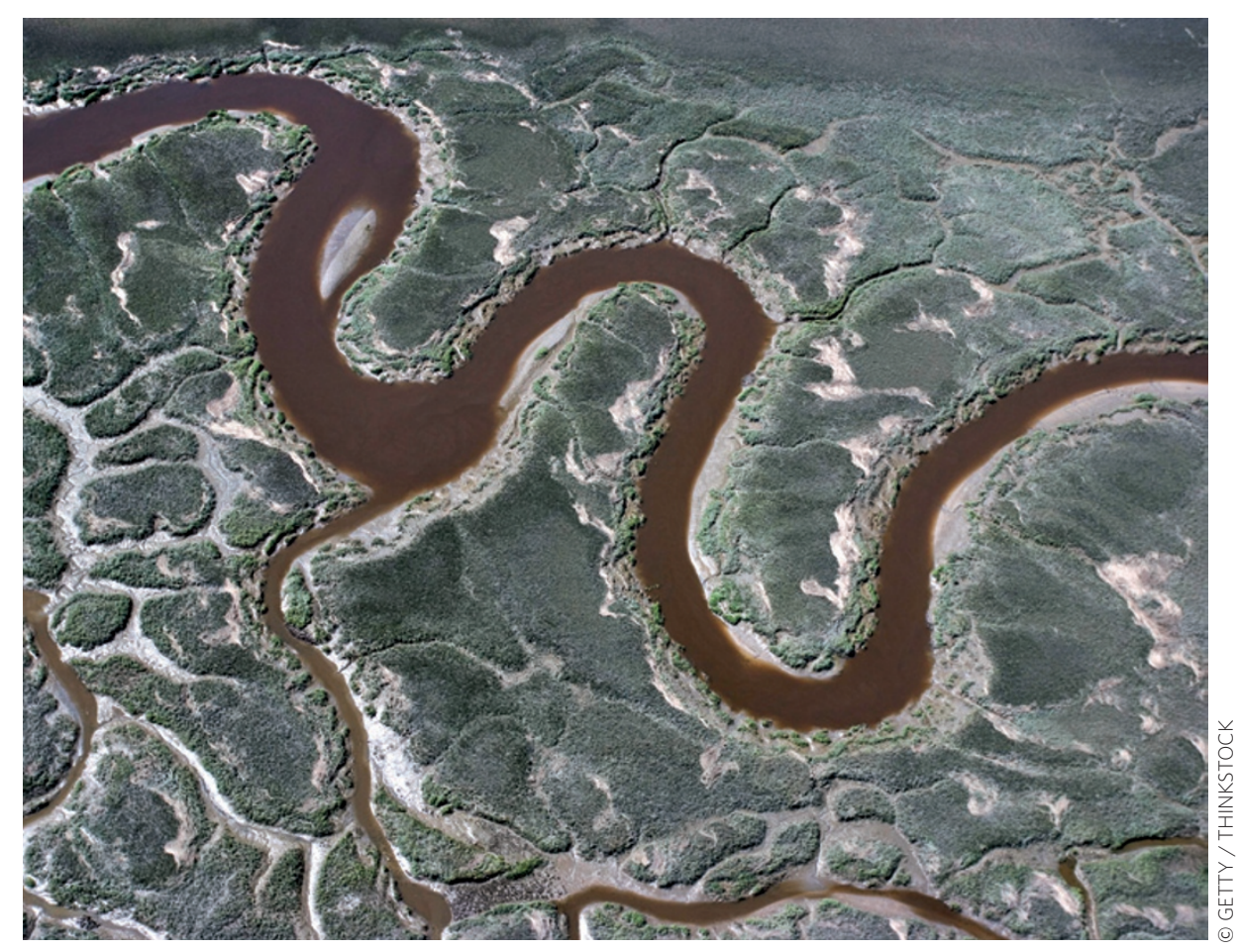

in the European Alps seem to metabolize carbon derived from upstream glaciers.

The climatic consequences of riverine out-gassing depend on whether rivers simply move the location of terrestrial carbon emissions and uptake, or if, instead, they alter the rate of carbon burial and release. Either way, an upward revision in the importance of inland waterways to continental carbon budgets may be on the cards. Small streams and rivers are emerging as particularly prominent sources of carbon dioxide and it is these waterways that are often missed in large-scale assessments of river biogeochemistry, argues a Commentary on page 678 .

The biogeochemical significance of waterways extends far beyond carbon, however. For instance, rivers serve as dumping grounds for a range of byproducts of human activity, including agricultural fertilizers, manure, sewage and industrial effluent. As a result, many rivers contain high concentrations of nitrogen, rendering them a significant source of the potent greenhouse gas nitrous oxide. The factors regulating nitrous oxide release have yet to be determined. Large-scale assessments of the global nitrous oxide budget, including those generated by the Intergovernmental Panel on Climate Change, have so far assumed that riverine nitrous oxide emissions scale linearly with inorganic nitrogen inputs. However, detailed measurements along the Grand River in Ontario, Canada, reported in a Letter on page 715 of this issue, suggest that oxygen levels are a more important determinant of nitrous oxide emissions, with low oxygen levels promoting release.

The role of rivers in global biogeochemical cycling and climate is not only poorly constrained at present, but is also likely to change in coming decades. Factors such as climate change, population growth and pressures on stretched freshwater supplies (Nature 488,197-200; 2012) will all contribute. It is high time that our understanding of the role of rivers in climate and carbon cycle dynamics caught up with the changes that are afoot. 